\title{
Türkiye'de Tarım, Sanayi ve Hizmet Sektörleri Arasındaki Nedensellik İlişkisinin Analizi
}

Nilcan MERT (https://orcid.org/0000-0002-4065-4768), Ardahan University, Turkey; nilcanmert@ardahan.edu.tr

Zehra ABDIOĞLU (https://orcid.org/0000-0002-1653-2840), Karadeniz Technical University, Turkey; maras@ktu.edu.tr

\section{Analysis of the Causality Relationship between Agriculture, Industry and Service Sectors in Turkey}

\begin{abstract}
This study aims to investigate the causal relationship between agriculture, industry, and service sectors for Turkey. For this purpose, the panel causality analysis developed by Dumitrescu and Hurlin (2012) was performed for Turkey's general and seven geographical regions, using panel data covering 81 provinces from 2004 to 2017 . Within the framework of this analysis, the key sectors that drive economic growth were examined for seven regions. According to the findings obtained from the panel causality test, the agriculture sector is fed by industry and service sectors, and the key sectors those direct general economic growth are different by region.

Keywords

Economic Growth, Sectoral Growth, Dumitrescu and Hurlin Causality Analysis.

JEL Classification Codes : O41, R11, C23.

\section{$\ddot{\mathbf{O} z}$}

Bu çalışmada Türkiye için tarım, sanayi ve hizmet sektörleri arasındaki nedensellik ilişkisinin araştırılması amaçlanmıştır. Bu amaç doğrultusunda 2004-2017 dönemi ile 81 ili kapsayan panel verileri kullanılarak Dumitrescu ve Hurlin (2012) tarafindan geliştirilen panel nedensellik analizi hem Türkiye geneli hem de yedi coğrafik bölge için gerçekleştirilmiştir. Analizler çerçevesinde bölgelere göre ekonomik büyümeye yön veren kilit sektörler belirlenmeye çalışılmıştır. Panel nedensellik testinden edinilen bulgulara göre tarım sektörü sanayi ve hizmet sektörlerinden beslenmektedir ve genel ekonomik büyümeye yön veren öncü sektörler bölgelere göre farklılık arz etmektedir.
\end{abstract}

Anahtar Sözcükler $\quad$ : Ekonomik Büyüme, Sektörel Büyüme, Dumitrescu ve Hurlin Nedensellik Analizi. 
Mert, N. \& Z. Abdioğlu (2021), “Türkiye'de Tarım, Sanayi ve Hizmet Sektörleri

Arasındaki Nedensellik İlișkisinin Analizi”, Sosyoekonomi, 29(50), 317-336.

\section{Giriş}

Ekonomik büyümede sektörel bağlantıların önemi Hirschman (1958) tarafindan dengesiz büyüme teorisi kapsamında savunulmuştur. Teori ekonominin tüm sektörlerine eş zamanlı olarak yatırım yapmak yerine ekonominin stratejik sektörlerine yatırım yapma gerekliliği üzerinde durmaktadır. Teoriye göre sektörler arasındaki bağlantıların etkisiyle ekonominin diğer sektörleri otomatik olarak kendilerini geliştirecektir. Hirschman (1958), ekonominin farklı sektörleri arasındaki bağlantıları ileri (forward) ve geri (backward) doğru bağlantılar olarak tanımlamaktadır. Ayrıca Thirlwall (2006) da sektörler arasındaki ileri ve geri doğru bağlantı mekanizmasını açıklamıştır. Thirlwall (2006)'a göre bir sektörün çıktısı bir başka sektörün girdisi olarak kullanılıyorsa bu durum ileri doğru aktarım mekanizması yaratır. Bir sektörün çıktısının üretimi başka bir sektörden girdi satın almayı gerektiriyorsa ilgili sektörler arasında geri doğru bir bağlantı oluşturur. (Kularatne \& Sivarajasingham, 2014: 27).

Ekonominin temel sektörlerinden biri olan tarım sektörü sanayileşme altyapısının oluşturulmasında elzem olan girdileri sağlamaktadır. Lewis (1954), Hirschman (1958), Fei ve Ranis (1961), Kuznets (1973) ve Chenery (1979), ekonomik kalkınmanın tarımsal faaliyetlerden endüstriyel aktivitelere doğru yapısal bir dönüşüm olduğunu ortaya koymuşlardır. Tarım sektörü, fiyat istikrarının temin edilmesinde çok önemli bir faktör olan yeterli gıda arzının sunulmasına imkân tanımaktadır. Tarımsal ihracat, önemli endüstriyel ara veya yatırım mallarını ithal etmek amacıyla kullanılabilen önemli bir döviz kaynağı niteliğindedir. Tarım sektörü tarım dışındaki sektörlere sermaye ve emek girdisi sağlamaktadır. Pazar odaklı bir ekonomi söz konusu olduğunda, kademeli olarak girişimcilik ve pazarlama yetenekleri birikimi yoluyla sanayileşme süreçlerini kolaylaştırmaktadır. Böylece daha hızlı bir tarım sektörü büyümesi sanayi sektöründe daha hızlı büyümeye neden olmaktadır. Özetle tarım sektörü, emek, sermaye ve hammadde kaynağı sağlayarak ve sanayi ürünlerine talep yaratarak sanayileşmeyi desteklemektedir. Aynı zamanda, tarım ve sanayi arasındaki ilişki karşılıklı bağımlılık ve tamamlayıcılık ilişkisini temsil etmektedir. Şöyle ki, tarım sektöründe sanayi sektörüne girdi sağlanırken aynı zamanda tarım sektörü verimliliğini artırmak için modern tarımsal girdileri, ileri teknolojileri ve tüketim mallarını da sanayi sektöründen temin etmektedir (Hwa, 1989: 107). Bu pozitif ilişki kaynak kullanımında daha fazla üretkenliğe ve sürdürülebilir ekonomik büyümeye yol açmaktadır. Diğer taraftan karşılaştırmalı üstünlük yasası tarımsal üretkenlik ve sanayileşme arasında negatif bir ilişkiye işaret etmektedir. Bu görüşe göre, imalat sektörü emek için tarım sektörü ile rekabet etmek zorundadır. Tarım sektöründeki düşük verimlilik, imalat sanayinin yararlanabileceği bol miktarda ucuz işgücü arzını ifade eder (Subramaniam \& Reed, 2009: 6).

Fuchs (1968), Blades vd. (1974), Gemmell (1982) ve Bhagwati (1984) hizmet sektörünün hizmet dışı sektörler ile olan bağlantısını ele alarak hizmet sektörünün tarım sektörüne dağıtım ve perakendecilik gibi aracılık hizmetleri sağlayabildiğini vurgulamışlardır. Dağıtım ve perakendecilik gibi aracılık hizmetlerinin hem tarıma hem de sanayiye katkısı zaman içinde ivme kazanmıştır. 
İmalat ve hizmet sektörlerinin iç içe geçtiği konusunda genel bir kanı söz konudur. İmalat sanayinin üretim süreçlerinde çeşitli hizmetleri önemli girdiler olarak kullandığı ve aynı zamanda sektörel çıktılarıyla birlikte bir dizi hizmet faaliyetini de yürütülmekte olduğu su götürmez bir gerçektir. Diğer taraftan, hizmet sektörü daha verimli aktivitelerde bulunmak amacıyla imalat sanayi çıktılarına ihtiyaç duymaktadır. Araştırmalar telekomünikasyon ve yazılım geliştirme gibi araştırma yoğun ve yüksek teknolojili hizmet endüstrilerinin imalat sanayinin girdilerinin önemli bir bölümünü oluşturduğunu ve aynı zamanda imalat sektöründeki pozitif ve önemli verimlilik etkilerinin de kaynağı olduğunu göstermiștir (Foster vd., 2012: 12).

"Nihai kullanım" hizmetleri tarım ve sanayi ürünlerine olan talebin yakın ikamesi olabilir ve hizmet sektörü çoğu zaman doğrudan işgücü için tarımla rekabet etmektedir (Gemmell vd., 2000: 356). Yüksek teknolojili sanayi ürünleri hizmet sektörüne daha fazla ihtiyaç duymaktadır ve özellikle taşımacılık, telekomünikasyon ve finansal hizmet sektörlerinin büyümesinin sanayi sektörünün gelişimi üzerinde önemli pozitif etkileri bulunmaktadır (Nordas \& Kim, 2013).

Kaldor, 1967'deki öncü çalı̧̧ması ile sanayi sektörünün ekonomik büyümenin motoru olduğunu kanıtlamıştır. Ancak yeni teknolojik gelişmeler ve diğer faktörler nedeniyle hizmetler sektörünün gelişmekte olan ülkelerde bile büyümenin motoru olarak sanayinin yerini alabileceğini öne süren alternatif görüşlerin mevcut olduğuna literatürde rastlanmaktadır (Dasgupta \& Singh, 2005). Hizmetler sektörü genel ekonomik büyümeye istikrarlı bir destek sağlamaktadır. Sınır ötesi ticaret ve doğrudan yabancı yatırımlarda önemli ve artan bir paya sahiptir. Hizmetler sektörünün yükselen trendinin, bilgiye dayalı ve beceri odaklı faaliyetler alanındaki ilerleme ile giderek artan bir öneme sahip olması beklenmektedir (Ahmed \& Ahsan, 2011: 1).

Ekonominin temel sektörleri arasındaki güçlü bağlantılar ve karşılıklı ilişkiler göz önüne alındığında sektörel gelişmeler ve sektörler arasındaki etkileşimlerin gerek sektörel bazda büyüme ve gerekse de genel ekonomik büyüme üzerinde önemli bir etkisinin olması beklenmektedir. Sektörler arasındaki geriye ve ileriye doğru bağlantılar konusunda bilgi sahibi olmak sektörler arası olası geri bildirim mekanizmaları hakkında daha iyi bir bakış açısı geliştirmeye olanak sağlayacaktır. Diğer sektörler ile önemli düzeyde geriye ve ileriye doğru bağlantı mekanizmasına sahip olan bir sektöre yatırımların yoğunlaştırılması kuşkusuz önem arz etmektedir. İlgili sektörün gelişimi üretim ve istihdam seviyeleri üzerinde önemli bir etkiye sahip olacaktır. Ekonominin kilit sektörü olarak değerlendirilen adı geçen sektördeki gelişme diğer sektörlerde daha fazla ekonomik faaliyeti teşvik ederek genel ekonomik büyüme üzerinde daha büyük bir çarpan etkisi yaratacaktır. Bu nedenle, sürdürülebilir bir ekonomik büyüme modelini yakalamak ve uzun vadeli stratejiler geliştirmek amacıyla sektörler arasındaki ilişkinin doğru bir şekilde yorumlanması elzemdir. Bu amaçla çalışmada Türkiye için 81 il ve 2004-2017 dönemini kapsayan panel veri analizi kullanılarak genel ekonomik büyüme ile tarım, sanayi ve hizmet sektörlerindeki büyüme arasındaki nedensellik ilişkisinin araştırılması amaçlanmıştır. Dumitrescu ve Hurlin 
hetorojen panel nedensellik testi kullanılarak hem Türkiye geneli hem de yedi coğrafik bölge bazında sektörler arası nedensellik ilişkisi araştırılmıştır.

Sektörler arası ilişkileri konu alan ampirik literatürde çalışmaların önemli bir bölümünün çok sayıda ülkenin girdi-çıktı tablolarını temel aldığı gözlenmiştir (Sastry vd., 2003, Ersungur \& Kızıltan, 2008; Atan, 2011; Ersungur vd., 2011; Günçavd1 vd., 2013; Yıldız \& Akduğan, 2014; Altan vd., 2015; Pehlivanoğlu \& İnce, 2020 vb.). İlgili çalışmalar özellikle tarım, hayvancılık, madencilik, gıda, enerji, inşaat, hizmet, ulaşım vb. sektörler arasındaki ileri ve geri doğru bağlantılar üzerinde durarak kilit sektörün belirlenmesine odaklanmıştır. Yüksek çarpan etkilerine sahip sektörlerin saptanması karar alıcılara yatırım tercihleri noktasında önemli bilgiler sağlamaktadır.

Girdi-çıktı tablolarına dayalı çalışmaların yanı sıra zaman serilerini kullanarak eş bütünleşme ve nedensellik yaklaşımları bazında sektörler arası dinamikler üzerinde duran çalışmaların da önemli sayıda olduğu dikkatleri çekmektedir (Yamak \& Sivri, 1997; Kanwar, 2000; Yao, 2000; Yamak, 2000; Katırcıŏlu, 2002; Wells \& Thirlwall, 2004; Terzi \& Oltulular, 2004; Rashid, 2004; Blunch \& Verner, 2006; Arısoy, 2008; Subramaniam \& Reed, 2009; Yamak vd., 2016; Kolcu \& Yamak, 2017; Yetiz \& Özden, 2017; Kalmaz \& Giritli, $2018 \mathrm{vb})$. Adı geçen çalışmalarda tarım, sanayi, hizmet vb. sektörler arasındaki hem uzun hem de kısa dönemli etkileşimlere dayalı olarak ekonomide öncü olan kilit sektörler tespit edilmiştir. Bunun yanı sıra genel ekonomik büyümeyi besleyen ya da genel ekonomik büyümeden beslenen sektörler de ilgili çalışmalar kapsamında ortaya konulmuştur.

Literatürde ekonominin genel sektörleri arasındaki ilişkiyi araştıran girdi-çıktı analizlerine ve zaman serisi yaklaşımlarına dayalı çalışmaların yanı sıra, çok sayıda gözlemle çalışmaya olanak sağlayan panel veri analizleri kapsamında sektörler arasındaki dinamik ilişkiyi araştıran çalışmaların nispeten sınırlı sayıda olduğunu söylemek mümkündür. Literatürdeki ilgili boşluğu doldurmak amacıyla bu çalışmada Türkiye için tarım, sanayi ve hizmet sektörleri arasındaki dinamik ilişki 81 il bazında 2004-2017 dönemine ilişkin panel veriler kullanılarak analiz edilmiştir. Çalışmada öncelikle kullanılan veri seti ve yöntem tanıtılmış daha sonra edinilen bulgular açıklanmıştır. Son olarak genel değerlendirmeye yer verilmiştir.

\section{Veri Seti ve Ekonometrik Yöntem}

Çalışmada 81 ile ilişkin 2004-2017 dönemine ait genel GSYİH ile tarım, sanayi ve hizmetler sektörlerine ilişkin GSYİH serileri kullanılmıştır. Türkiye İstatistik Kurumu Bölgesel İstatistikler veri tabanından çekilen veri seti tüketici fiyatları endeksi (TÜFE, 2009=100) ile reel hale dönüştürülmüştür. Reel serilerin logaritmik dönüşümleri yapılarak logaritmik farkları alınmıştır. Bu şekilde sektörlere ait büyüme serileri ile analizler gerçekleştirilmiştir. 
Tablo: 1

\section{Değişken Tanımları}

\begin{tabular}{|l|l|l|}
\hline Değişken & Açılama & Tanım \\
\hline Dlrgsyih & Reel gayri safi yurtiçi hâsıla büyüme serisi & lrgsyih-lrgsyih(-1) \\
\hline Dlrtarim & Tarım sektörü reel gayri safi yurtiçi hâsıla büyüme serisi & lrtarim-lrtarim(-1) \\
\hline Dlrsanayi & Sanayi sektörü reel gayri safi yurtiçi hâsıla büyüme serisi & lrsanayi-lrsanayi(-1) \\
\hline Dlrhizmet & Hizmetler sektörü reel gayri safi yurtiçi hâsıla büyüme serisi & lrhizmet-lrhizmet(-1) \\
\hline l, serilerin logaritmik dönüşümünün yapıldığını; D, serilerin birinci devresel farkının alındığını göstermektedir. \\
\hline
\end{tabular}

Tablo 2'de değişkenlere ilişkin tanımlayıcı istatistikler sunulmuştur. 2004-2017 dönemi için 81 il bazında ortalama genel ekonomik büyüme yaklaşı 0,04 oranında gerçekleşirken sanayi sektörü 0,06 , tarım sektörü 0,01 ve hizmet sektörü 0,04 ortalama büyüme sergilemiştir. En yüksek standart sapma değerine sahip sektörün tarım sektörü olduğu dikkatleri çekmektedir. Jarque-Bera test istatistikleri büyüme serilerinin normal dağılıma sahip olmadıklarını göstermektedir.

Tablo: 2

\section{Tanımlayıcı İstatistikler}

\begin{tabular}{|c|c|c|c|c|}
\hline & Dlrgsyih & Dlrtarım & Dlrsanayi & Dlrhizmet \\
\hline Ortalama & 0,045713 & 0,014672 & 0,069537 & 0,047192 \\
\hline Medyan & 0,045094 & 0,009941 & 0,073077 & 0,047578 \\
\hline Maksimum & 0,228979 & 1,077461 & 0,416453 & 0,174081 \\
\hline Minimum & $-0,118337$ & $-0,800882$ & $-0,342901$ & $-0,075854$ \\
\hline Std. Sapma & 0,049161 & 0,151658 & 0,098181 & 0,034461 \\
\hline Eğiklik & 0,040402 & 0,685130 & $-0,503778$ & $-0,356328$ \\
\hline Basıklik & 4,047705 & 8,896657 & 4,787097 & 4,041635 \\
\hline Jarque-Bera & 48,44740 & 1607,939 & 184,6648 & 69,88769 \\
\hline Olasılık & 0,000000 & 0,000000 & 0,000000 & 0,000000 \\
\hline
\end{tabular}

Sektörel büyüme serileri arasındaki nedensellik analizine geçmeden çalışmada öncelikle paneli oluşturan birimler arasında yatay kesit bağımlılık olup olmadığ araştırılmıştır. Yatay kesit bağımlılık için Breusch ve Pagan (1980)'ın Lagrange Çarpanı testi (LM), Pesaran (2004)'ın yatay kesit bağımlılık testi (CD) ve Pesaran (2004)'ın ölçeklendirilmiş Lagrange Çarpanı testi $\left(\mathrm{LM}_{\mathrm{S}}\right)$ kullanılmıştır.

Yatay kesit bağımlılık testi için Breusch ve Pagan (1980) tarafından geliştirilen LM test istatistiğini hesaplamak amacıyla aşağıdaki (1) numaralı denklem tahmin edilmektedir.

$$
y_{i t}=\alpha_{i}+\beta_{i}^{\prime} x_{i t}+u_{i t} i=1,2, \ldots, N ; t=1,2, \ldots, T
$$

(1) numaralı denklemde i, yatay kesit boyutu; t, zaman boyutunu; $x_{i t}, \mathrm{kx} 1$ boyutundaki açıklayıcı değişkenler vektörünü; $\alpha_{i}$ ve $\beta_{i}$, sırasıyla bireysel sabitleri ve eğim katsayılarını göstermektedir. LM testinde yatay kesit bağımlılık olmadığını ifade eden sıfır hipotezi $\left(H_{0}: \operatorname{Cov}\left(u_{i t}, u_{j t}\right)=0\right.$ tüm $t^{\prime} l e r$ ve $\left.i \neq j i c ̧ i n\right)$ yatay kesit bağımlılığ1 temsil eden alternatif hipoteze $\left(H_{1}: \operatorname{Cov}\left(u_{i t}, u_{j t}\right) \neq 0\right.$ en azından bir çift $i \neq j$ için) karşı test edilmektedir. LM test istatistiği (2) numaralı eşitlikte verilmiştir.

$$
L M=\sum_{i=1}^{N-1} \sum_{j=i+1}^{N} T_{i j} \hat{\rho}_{i j}^{2} \rightarrow \frac{\chi_{\frac{N(N-1)}{2}}^{2}}{2}
$$


$\hat{\rho}_{i j}$ her bir i için denklem (1)'in sıradan en küçük kareler yaklaşımıyla tahmini sonucu elde edilen hata terimlerine ilişkin korelasyon katsayısıdır. Breusch-Pagan testi panelin birim boyutunun nispeten küçük, zaman boyutunun ise büyük olması durumlarında uygun bir yaklaşımdır. LM test istatistiği büyük $\mathrm{N}$ durumunda uygun bir yaklaşım değildir. Pesaran (2004) bu eksikliği gidermek amacıyla LM istatistiğinin standardize versiyonunu geliştirmiştir. İlgili test istatistiği (3) numaralı eşitlikte gösterilmiştir.

$$
L M_{S}=\sqrt{\frac{1}{N(N-1)}} \sum_{i=1}^{N-1} \sum_{j=i+1}^{N}\left(T_{i j} \hat{\rho}_{i j}^{2}-1\right) \rightarrow N(0,1)
$$

Pesaran (2004), LM ve $\mathrm{LM}_{\mathrm{S}}$ istatistiklerindeki boyut bozulmasını (size distortion) düzeltmek için korelasyon katsayılarının $\left(\hat{\rho}_{i j}\right)$ ortalamasına dayalı alternatif bir test istatistiği geliştirmiştir. CD test istatistiği (4) numaralı eşitlikte sunulmuştur.

$$
C D=\sqrt{\frac{2}{N(N-1)}} \sum_{i=1}^{N-1} \sum_{j=i+1}^{N} T_{i j} \hat{\rho}_{i j} \rightarrow N(0,1)
$$

Yatay kesit bağımlılık durumunda panel veriler için birim kök analizinde ikinci nesil panel birim kök testlerinin kullanımı önem arz etmektedir. Pesaran (2007), yatay kesit genelleştirilmiş Dickey-Fuller (CADF) regresyonu üzerinden standart birim kök istatistiğine dayanan bir birim kök testi önermiştir. Standart ADF denklemine yatay kesit ortalamalara ilişkin gecikmeli değerler ve yatay kesit ortalamalarının birinci farkları eklenerek CADF denklemi tahmin edilmektedir. Pesaran (2007)'ın yaklaşımı bireysel yatay kesit ortalamalarla genişletilmiş $\mathrm{ADF}$ istatistiklerinin $\left(\mathrm{CADF}_{\mathrm{i}}\right)$ basit aritmetik ortalamalarına dayanmaktadır. Bireysel CADF istatistikleri CIPS (yatay kesit genişletilmiş Im, Pesaran ve Shin) istatistiğinin elde edilmesinde kullanılmaktadır. CIPS istatistiğine (5) numaralı eşitlikte yer verilmiştir.

$$
\text { CIPS }=N^{-1} \sum_{i=1}^{N} C A D F_{i}
$$

Yatay kesit bağımlılığın yanı sıra panel veri analizlerinde bir diğer önemli konu eğim katsayılarının homojenliğidir. Eğim katsayılarının homojenlik testinde Pesaran ve Yamagata (2008) tarafından önerilen $\Delta$ ve $\Delta_{\text {adj }}$ testlerinden yararlanılmıştır. Pesaran ve Yamagata (2008)'in $\Delta$ testi, Swamy (1970)'in eğim katsayısı homojenlik testinin standardize bir versiyonudur. Swamy (1970)'in test istatistiği aşağıdaki gibidir:

$$
\tilde{S}=\sum_{i=1}^{N}\left(\hat{\beta}_{i}-\tilde{\beta}_{W F E}\right)^{\prime} \frac{x_{i}^{\prime} M_{\tau} x_{i}}{\widetilde{\sigma}_{i}^{2}}\left(\hat{\beta}_{i}-\tilde{\beta}_{W F E}\right)
$$

(6) numaralı eşitlikte $\hat{\beta}_{i}$ havuzlanmış en küçük kareler tahmincisini; $\tilde{\beta}_{W F E}$, ağırlıklı sabit etkiler havuzlanmış tahmincisini; $M_{\tau}$, birim matrisi ve $\tilde{\sigma}_{i}^{2}, \sigma_{i}^{2}$ 'nin tahmincisini ifade etmektedir. $\Delta$ istatistiği aşağıdaki (7) numaralı eşitlikte gösterilmiş̧tir.

$$
\widetilde{\Delta}=\sqrt{N}\left(\frac{N^{-1} \tilde{S}-k}{\sqrt{2 k}}\right) \rightarrow(N, T) \rightarrow \infty
$$


Pesaran ve Yamagata (2008), $\Delta$ test istatistiğine ortalama ve varyans yanlılık düzeltmesi uygulayarak testin küçük örneklem durumunda da geçerliliğini sağlamışlardır. (8) numaralı eşitlikte $\widetilde{\Delta}_{a d j}$ test istatistiği verilmiştir.

$$
\widetilde{\Delta}_{a d j}=\sqrt{N}\left(\frac{N^{-1} \tilde{S}-E\left(\tilde{z}_{i t}\right)}{\sqrt{\operatorname{var}\left(\tilde{z}_{i t}\right)}}\right)
$$

Gerek yatay kesit bağımlılık ve gerekse de homojenlik testlerine ilişkin bulgular göz önüne alınarak çalışmada genel ekonomik büyüme ve sektörel büyüme arasındaki ilişkiyi analiz etmek amaciyla Dumitrescu ve Hurlin (2012) tarafından önerilen heterojen panel nedensellik testi kullanılmıştır. Dumitrescu ve Hurlin (2012), heterojen panel veri modelleri için çok basit bir Granger (1969) nedensellik testi önermişlerdir. Önerdikleri test istatistiği bireysel Wald istatistiklerinin ortalamasına dayanmaktadır. Monte Carlo deneyleri standardize panel istatistiklerinin yatay kesit bağımlılığın varlığı durumunda bile çok iyi küçük örnek özelliklerine sahip olduğunu kanıtlamıştır.

$X$ ve $Y$ durağan iki seriyi göstermek üzere doğrusal model aşağıdaki gibi yazılır:

$$
Y_{i, t}=\alpha_{i}+\sum_{k=1}^{K} \gamma_{i}^{(k)} Y_{i, t-k}+\sum_{k=1}^{K} \beta_{i}^{(k)} X_{i, t-k}+\varepsilon_{i, t}
$$

(9) numaralı denklemde $i=1,2, \ldots, N$ ve $t=1,2, \ldots, T$ olmak üzere $\beta_{i}=$ $\left(\beta_{i}^{(1)}, \ldots, \beta_{i}^{(K)}\right)^{\prime}$. Dumitrescu ve Hurlin yaklaşımında sıfır hipotezi (Homogeneous Non Causality, HNC) aşağıdaki gibi herhangi bir yatay kesit için nedensellik yoktur şeklinde tanımlanmaktadır.

$$
H_{0}: \beta_{i}=0, \forall_{i}=1, \ldots, N
$$

Buna karşın alternatif hipotez ise $\mathrm{N}_{1}+1$ 'den N'e kadar olan yatay kesit birimler için $X$ 'den $Y$ 'ye doğru bir nedensellik ilişkisi olduğunu ancak 1. birimden $\mathrm{N}_{1}$. birime kadar herhangi bir nedensellik olmadığını ifade etmektedir. Diğer bir ifadeyle alternatif hipotez nedensellik ilişkisinin bazı birimler için söz konusu olduğunu (heterojen) göstermektedir.

$$
\begin{array}{ll}
H_{1}: \quad & \beta_{i}=0, \forall_{i}=1, \ldots, N_{1} \\
& \beta_{i} \neq 0, \forall_{i}=N_{1}+1, N_{1}+2, \ldots, N
\end{array}
$$

Dumitrescu ve Hurlin (2012), $W_{N, T}^{H n c}$ ortalama test istatistiğini (10) numaralı eşitlikteki gibi tanımlamışlardır.

$$
W_{N, T}^{H n c}=\frac{1}{N} W_{i, T}
$$

(10) numaralı eşitlikte $W_{i, T}$, bireysel $H_{0}: \beta_{i}=0$ testine karşılık gelen $i$. kesit birimi için bireysel Wald istatistiklerini temsil etmektedir. Dumitrescu ve Hurlin (2012), sıfır hipotezi altında ortalama test istatistiğinin $\left(W_{N, T}^{H n c}\right)$ asimtotik dağılımını ilk olarak $T$ 'nin ve 
sonra N'in sonsuza yakınsaması durumlarında ele almışlardır. Bu durumda standardize istatistik (11) numaralı eşitlikteki gibi tanımlanmıştır.

$$
Z_{N, T}^{H n c}=\sqrt{\frac{N}{2 K}}\left(W_{N, T}^{H n c}-K\right) \frac{d}{T, N \rightarrow \infty} N(0,1)
$$

Büyük $N$ ve $T$ için standartlaştırılmış istatistik $Z_{N, T}^{H n c}$, belirli bir anlamlılık düzeyinde, karşılık gelen normal kritik değerin üstündeyse sıfır hipotezi (HNC) reddedilmektedir. Aynı zamanda $\mathrm{T}>5+2 \mathrm{~K}$ olan sabit bir $\mathrm{T}$ boyutu için standardize $\mathrm{Z}$ istatistiği standart normal dağılım izler.

$$
\tilde{Z}_{N}^{H n c}=\sqrt{\frac{N}{2 K} \frac{(T-2 K-5)}{(T-K-3)}}\left[\frac{(T-2 K-3)}{(T-2 K-1)} W_{N, T}^{H n c}-K\right] \frac{d}{N \rightarrow \infty} N(0,1)
$$

Eğer (12) numaralı eşitlikteki standartlaştırılmış istatistik $\tilde{Z}_{N}^{H n c}$, belirli bir anlamlılık düzeyinde, karşılık gelen normal kritik değerin üstündeyse, sıfır hipotezi (HNC) reddedilir. Dumitrescu ve Hurlin (2012), panel veriler arasındaki yatay kesit bağımlılı̆̆ın bir testin küçük örneklem özellikleri üzerindeki negatif etkilerini dikkate almak amacıyla nedensellik analizinde asimptotik kritik değerler yerine bootstrap kritik değerlerini kullanmışlardır.

\section{Analiz Bulguları}

Sektörel büyüme serileri arasındaki nedensellik analizi için uygun yaklaşımı belirlemek amacıyla öncelikle yatay kesit bağımlılık ve homojenlik testleri yapılmıştır. Tablo 3'te yatay kesit bağımlılık testlerine ilişkin bulgulara yer verilmiştir. Tablodan gözleneceği üzere kullanılan tüm yaklaşımlar $\% 1$ anlamlılık düzeyinde yatay kesit bağımlılığa işaret etmektedir. Bu bulgu Türkiye'nin illerinden birinde bir şok meydana geldiğinde iller arasındaki ekonomik ve sosyal entegrasyon dolayısıyla bu şokun diğer illere yayılabileceğini doğrulamaktadır.

\section{Tablo: 3}

\begin{tabular}{|c|c|c|c|c|}
\hline & Dlrgsyih & Dlrtarim & Dlrsanayi & Dlrhizmet \\
\hline LM (Breusch ve Pagan, 1980) & $15622,20^{* * * *}$ & $7817,48 * * *$ & $22085,14 * * *$ & $20476,82^{* * * *}$ \\
\hline LMs (Pesaran, 2004) & $152,81 * * *$ & $55,85^{* * * *}$ & $233,09 * * *$ & $213,11 * * *$ \\
\hline CD (Pesaran, 2004) & $115,14 * * *$ & $67,49 * * *$ & $144,85 * * *$ & $138,35 * * *$ \\
\hline
\end{tabular}

\section{Yatay Kesit Bă̆ımlılık Testi}

Sektörel büyüme serileri arasındaki karşılıklı dinamik bağımlılık ilişkisinin Dumitrescu ve Hurlin nedensellik yaklaşımı çerçevesinde araştırılması amacıyla değişkenlerin birim kök analizleri gerçekleştirilmiştir. İller arasındaki güçlü yatay kesit bağımlılık nedeniyle birim kök analizleri ikinci nesil birim kök testlerinden Pesaran (2007)'ın CADF yaklaşımı kullanılarak yapılmıştır. Tablo 4'te Pesaran (2007)'ın ikinci nesil birim kök analizine ilişkin bulgulara yer verilmiştir. Sabitli ve sabitli-trendli model sonuçları tüm büyüme serilerinin seviyelerinde durağan olduklarını göstermektedir. 
Tablo: 4

Pesaran (2007) CADF Birim Kök Analizi

\begin{tabular}{|l|c|c|}
\hline & Sabit & $\begin{array}{c}\text { Sabit+trend } \\
{[\text { Z-tbar }]}\end{array}$ \\
\hline Dlrgsyih & $-15,13^{* * *}$ & $-9,936^{* * *}$ \\
\hline Dlrtarim & $-18,99^{* * *}$ & $-13,413^{* * *}$ \\
\hline Dlrsanayi & $-11,055^{* * *}$ & $-8,632^{* * *}$ \\
\hline Drrhizmet & $-13,579^{* * *}$ & $-10,145^{* * *}$ \\
\hline \multicolumn{2}{|l|}{ Optimal gecikme uzunlukları Akaike bilgi kriterine göre 0 olarak belirlenmiştir. ***; prob $<0,01}$. & \\
\hline
\end{tabular}

Tablo 5'te Pesaran ve Yamagata (2008)'nın eğim homojenlik testine ilişkin bulgular sunulmuştur. $\tilde{\Delta}$ ve $\tilde{\Delta}_{a d j}$ istatistiklerine bakıldığında $\% 1$ anlamlılık düzeyinde eğim homojenliğini ifade eden sıfır hipotezinin reddedildiği gözlenmektedir. Elde edilen bu bulgular nedensellik yaklaşımı olarak hem yatay kesit bağımlılığı hem de heterojenliği dikkate alan Dumitrescu ve Hurlin panel nedensellik yaklaşımının uygun olduğu yönünde bilgi sağlamaktadır.

Tablo: 5

\section{Homojenlik Testi}

\begin{tabular}{|l|c|c|}
\hline & $\tilde{\Delta}$ (Pesaran ve Yamagata, 2008) & $\tilde{\Delta}_{\text {adj }}$ (Pesaran ve Yamagata, 2008) \\
\hline Dlrgsyih & $17,958^{* * *}$ & $22,893^{* * *}$ \\
\hline Dlrtarim & $11,898^{* * *}$ & $15,168^{* * *}$ \\
\hline Dlrsanayi & $15,396^{* * *}$ & $19,627^{* * *}$ \\
\hline Dlrhizmet & $15,396^{* * *}$ & $19,626^{* * *}$ \\
\hline$* * * ; p<0,01$ & & \\
\hline
\end{tabular}

Çalışmada 2004-2017 dönemi için 81 ilden oluşan panel veri seti kullanılarak gerek genel ekonomik büyüme ile sektörel büyüme arasındaki nedenselliği ve gerekse de sektörler arasındaki dinamik bağımlılığı araştırmak amacıyla Dumitrescu ve Hurlin nedensellik analizi gerçekleştirilmiştir. Bölgesel farklılıkları açığa çıkarmak amacıyla ilgili analizler hem Türkiye geneli hem de yedi coğrafik bölge kapsamında yapılmıştır. Tablolarda öncelikle genel ekonomik büyüme ile tarım, sanayi ve hizmet sektörleri arasındaki nedensellik bulgularına yer verilmiş ardından sektörler arasındaki nedensellik analizlerine dair sonuçlar raporlanmıştır. Türkiye geneline ilişkin sektörel nedensellik bulguları Tablo 6'da sunulmuştur.

Tablo: 6

Türkiye Geneli İçin Dumitrescu ve Hurlin Nedensellik Analizi

\begin{tabular}{|c|c|}
\hline Nedenselliğin Yönü & $\begin{array}{c}\text { Test istatistiği } \\
\text { (Z-bar) }\end{array}$ \\
\hline Dlrgsyih $\rightarrow$ Dlrhizmet & $\begin{array}{c}11,2233^{*}(1) \\
{[0,0740]}\end{array}$ \\
\hline Dlrhizmet $\rightarrow$ Dlrgsyih & $\begin{array}{c}4,4895(1) \\
{[0,2340]}\end{array}$ \\
\hline Dlrgsyih $\rightarrow$ Dlrsanayi & $\begin{array}{c}6,2820(1) \\
{[0,1940]}\end{array}$ \\
\hline Dlrsanayi $\rightarrow$ Dlrgsyih & $\begin{array}{c}11,2918^{*}(1) \\
{[0,0580]}\end{array}$ \\
\hline Dlrgsyih $\rightarrow$ Dlrtarim & $\begin{array}{c}13,3923^{*}(2) \\
{[0,0800]}\end{array}$ \\
\hline Dlrtarim $\rightarrow$ Dlrgsyih & $\begin{array}{c}7,7957^{*}(1) \\
{[0,0720]}\end{array}$ \\
\hline
\end{tabular}




\begin{tabular}{|c|c|}
\hline Dlrtarim $\rightarrow$ Dlrsanayi & $\begin{array}{c}1,5263(1) \\
{[0,5000]}\end{array}$ \\
\hline Dlrsanayi $\rightarrow$ Dlrtarim & $\begin{array}{c}16,5935^{*}(2) \\
{[0,0520]}\end{array}$ \\
\hline Dlrhizmet $\rightarrow$ Dlrsanayi & $\begin{array}{c}0,9292(1) \\
{[0,8340]}\end{array}$ \\
\hline Dlrsanayi $\rightarrow$ Dlrhizmet & $\begin{array}{c}4,1054(1) \\
{[0,2660]}\end{array}$ \\
\hline Dlrhizmet $\rightarrow$ Dlrtarim & $\begin{array}{c}15,1555^{* *}(1) \\
{[0,0360]}\end{array}$ \\
\hline Dlrtarim $\rightarrow$ Dlrhizmet & $\begin{array}{c}8,0740^{*}(1) \\
{[0,0700]}\end{array}$ \\
\hline
\end{tabular}

Tablo 6 incelendiğinde genel ekonomik büyümeden hizmetler sektörüne ve sanayi sektörü büyümesinden genel ekonomik büyümeye doğru tek yönlü bir nedensellik ilişkisinin söz konusu olduğu gözlenmektedir. Ayrıca tarım sektöründeki büyüme ile genel ekonomik büyüme arasında çift yönlü nedensellik ilişkisinin varlığı dikkatleri çekmektedir. Bu bulgular kapsamında genel ekonomik büyümeye ivme kazandıran sektörlerin sanayi ve tarım sektörleri olduğu, hizmetler sektörünün ise genel ekonomik büyümeden beslendiği söylenebilir. Sektörler arasındaki ilişki bazında sanayi sektöründeki büyümeden tarım sektöründeki büyümeye doğru tek yönlü ve hizmetler sektöründeki büyüme ile tarım sektöründeki büyüme arasında ise çift yönlü bir nedensellik ilişkisi olduğu, sanayi ve hizmet sektörleri arasında herhangi bir nedensellik ilişkisi bulunmadığı yönünde bulgulara ulaşılmıştır. Tarım ve hizmet sektörleri arasındaki karşılıklı ilişki iki sektör arasındaki ileri ve geri doğru aktarım mekanizmasının varlığı için bir kanıt olarak değerlendirilebilir.

Çalışmada yedi coğrafik bölgeye ilişkin sektörel nedensellik ilişkileri de araştırılarak bölgesel farklılıkların ortaya konulması amaçlanmıştır. Öncelikle Marmara Bölgesi için nedensellik analizi bulgularına Tablo 7'de yer verilmiştir. Buna göre Marmara Bölgesi için yalnızca hizmet sektöründeki büyümeden tarım sektöründeki büyümeye doğru tek yönlü anlamlı bir nedensellik ilişkisi tespit edilmiştir. Bunun dışında sektörler arasında anlamlı bir ileri veya geri doğru bir aktarım mekanizmasına rastlanılmamıştır.

Tablo: 7

Marmara Bölgesi İçin Dumitrescu ve Hurlin Nedensellik Analizi

\begin{tabular}{|l|c|}
\hline Nedenselliğin Yönü & $\begin{array}{c}\text { Test istatistiği } \\
\text { (Z-bar) }\end{array}$ \\
\hline \multirow{2}{*}{ Dlrgsyih $\rightarrow$ Dlrhizmet } & $\begin{array}{c}1,7257(1) \\
{[0,2780]}\end{array}$ \\
\hline \multirow{2}{*}{ Dlrhizmet $\rightarrow$ Dlrgsyih } & $-0,0085(1)$ \\
& {$[0,9960]$} \\
\hline Dlrgsyih $\rightarrow$ Dlrsanayi & $1,1185(2)$ \\
& {$[0,6340]$} \\
\hline \multirow{2}{*}{ Dlrsanayi $\rightarrow$ Dlrgsyih } & $1,9555(2)$ \\
\multirow{2}{*}{ Dlrgsyih $\rightarrow$ Dlrtarim } & {$[0,4460]$} \\
\hline \multirow{2}{*}{ Dlrtarim $\rightarrow$ Dlrgsyih } & $4,6991(2)$ \\
& {$[0,1240]$} \\
\hline \multirow{2}{*}{ Dlrtarim $\rightarrow$ Dlrsanayi } & $-1,3170(1)$ \\
& {$[0,3300]$} \\
\hline \multirow{2}{*}{ Dlrsanayi $\rightarrow$ Dlrtarim } & $0,1762(2)$ \\
& {$[0,9420]$} \\
\hline
\end{tabular}


Mert, N. \& Z. Abdioğlu (2021), “Türkiye'de Tarım, Sanayi ve Hizmet Sektörleri Arasındaki Nedensellik İlişkisinin Analizi”, Sosyoekonomi, 29(50), 317-336.

\begin{tabular}{|l|c|}
\hline Dlrhizmet $\rightarrow$ Dlrsanayi & $1,4380(2)$ \\
& {$[0,5800]$} \\
\hline Dlrsanayi $\rightarrow$ Dlrhizmet & $1,1760(2)$ \\
& {$[0,6320]$} \\
\hline Dlrhizmet $\rightarrow$ Dlrtarim & $6,1815^{*}(2)$ \\
& {$[0,0680]$} \\
\hline Dlrtarim $\rightarrow$ Dlrhizmet & $-0,5560(1)$ \\
\hline $\begin{array}{l}\text { Parantez içindeki değerler Akaike Bilgi Kriterine (AIC) göre belirlenmiş optimal gecikme uzunluklarını göstermektedir. Bootstrap sayıs } 500 \text { olarak } \\
\text { kullanılmıştrr. Köşeli parantez içinde olasılık değerlerine yer verilmiştir. ***, prob<0,01; **, prob<0,05 ve *,prob<0,10 }\end{array}$ \\
\hline
\end{tabular}

Ege Bölgesine ilişkin bulgular Tablo 8'de sunulmuştur. Bulgular Ege Bölgesi için hizmetler sektöründeki gelişmenin genel ekonomik büyümeyi beslediğini, genel ekonomik büyümenin ise tarım sektörünün gelişmesine katkıda bulunduğunu göstermiştir. Sektörler arasındaki ilişki incelendiğinde hem sanayi hem de hizmetler sektöründen tarım sektörüne doğru tek yönlü bir nedensellik ilişkisi olduğu dikkatleri çekmektedir. İlgili nedensellik bulguları değerlendirildiğinde Ege Bölgesi için özellikle hizmetler sektöründeki gelişmenin tarım sektöründeki gelişmeyi $\% 1$ anlamlılık düzeyinde önemli ölçüde etkilediği dikkatleri çekmektedir. Diğer bir ifadeyle hizmetler sektörünün tarım sektörü ile güçlü ileri dönük ilişkisi söz konusudur.

Tablo: 8

Ege Bölgesi İçin Dumitrescu ve Hurlin Nedensellik Analizi

\begin{tabular}{|c|c|}
\hline Nedenselliğin Yönü & $\begin{array}{c}\text { Test istatistiği } \\
\text { (Z-bar) }\end{array}$ \\
\hline Dlrgsyih $\rightarrow$ Dlrhizmet & $\begin{array}{c}1,4283(1) \\
{[0,3540]}\end{array}$ \\
\hline Dlrhizmet $\rightarrow$ Dlrgsyih & $\begin{array}{c}8,0428^{*}(2) \\
{[0,0860]}\end{array}$ \\
\hline Dlrgsyih $\rightarrow$ Dlrsanayi & $\begin{array}{c}-0,6211(1) \\
{[0,7320]}\end{array}$ \\
\hline Dlrsanayi $\rightarrow$ Dlrgsyih & $\begin{array}{c}-0,0660(1) \\
{[0,9840]}\end{array}$ \\
\hline Dlrgsyih $\rightarrow$ Dlrtarim & $\begin{array}{c}6,6490^{*}(2) \\
{[0,0500]}\end{array}$ \\
\hline Dlrtarim $\rightarrow$ Dlrgsyih & $\begin{array}{c}2,0982(2) \\
{[0,3040]}\end{array}$ \\
\hline Dlrtarim $\rightarrow$ Dlrsanayi & $\begin{array}{c}1,6303(2) \\
{[0,4200]}\end{array}$ \\
\hline Dlrsanayi $\rightarrow$ Dlrtarim & $\begin{array}{c}5,5650^{*}(2) \\
{[0,0860]}\end{array}$ \\
\hline Dlrhizmet $\rightarrow$ Dlrsanayi & $\begin{array}{c}0,7645(1) \\
{[0,7040]}\end{array}$ \\
\hline Dlrsanayi $\rightarrow$ Dlrhizmet & $\begin{array}{c}1,4773(1) \\
{[0,3640]}\end{array}$ \\
\hline Dlrhizmet $\rightarrow$ Dlrtarim & $\begin{array}{c}13,1343^{* * *}(2) \\
{[0,008]}\end{array}$ \\
\hline Dlrtarim $\rightarrow$ Dlrhizmet & $\begin{array}{c}1,0827(2) \\
{[0,5280]}\end{array}$ \\
\hline
\end{tabular}

İç Anadolu bölgesi için Dumitrescu ve Hurlin nedensellik analizi sonuçları Tablo 9'da verilmiştir. Tabloya göre sanayi sektöründeki gelişme genel ekonomik büyümeyi $\% 5$ anlamlılık düzeyinde açıklamaktadır. Bunun yanı sıra tarım sektörü büyümesi ile genel ekonomik büyüme arasında çift yönlü anlamlı bir nedensellik ilişkisi mevcuttur. Sektörler arasındaki ilişki bazında bulgular değerlendirildiğinde ise $\% 5$ anlamlılık düzeyinde sanayi sektöründeki gelişmenin tarım sektöründeki gelişmeye ivme kazandırdığını ifade edebiliriz. 
$\mathrm{Bu}$ durumu sanayi sektöründen tarım sektörüne doğru ileri doğru güçlü bir bağlantı mekanizmasının varlığı ile açıklayabiliriz. Buna karşın sanayi sektörünün tarım sektörüyle geri doğru bağlantısının zayıf olduğunu değerlendirebiliriz. Ayrıca İç Anadolu Bölgesi için ekonominin öncü sektörlerinin tarım ve sanayi olduğu vurgulanabilir.

Tablo: 9

İç Anadolu Bölgesi İçin Dumitrescu ve Hurlin Nedensellik Analizi

\begin{tabular}{|c|c|}
\hline Nedenselliğin Yönü & $\begin{array}{l}\text { Test istatistiği } \\
\text { (Z-bar) }\end{array}$ \\
\hline Dlrgsyih $\rightarrow$ Dlrhizmet & $\begin{array}{c}1,9298(1) \\
{[0,2120]}\end{array}$ \\
\hline Dlrhizmet $\rightarrow$ Dlrgsyih & $\begin{array}{c}2,6494(1) \\
{[0,2080]}\end{array}$ \\
\hline Dlrgsyih $\rightarrow$ Dlrsanayi & $\begin{array}{c}0,5704(1) \\
{[0,8000)}\end{array}$ \\
\hline Dlrsanayi $\rightarrow$ Dlrgsyih & $\begin{array}{c}8,6909^{* *}(1) \\
{[0,0180]}\end{array}$ \\
\hline Dlrgsyih $\rightarrow$ Dlrtarim & $\begin{array}{c}7,4502^{* *}(1) \\
{[0,0360]}\end{array}$ \\
\hline Dlrtarim $\rightarrow$ Dlrgsyih & $\begin{array}{c}6,6076^{*}(2) \\
{[0,068]}\end{array}$ \\
\hline Dlrtarim $\rightarrow$ Dlrsanayi & $\begin{array}{c}1,4967(2) \\
{[0,4580]}\end{array}$ \\
\hline Dlrsanayi $\rightarrow$ Dlrtarim & $\begin{array}{c}8,1926^{* * *}(1) \\
{[0,0300]}\end{array}$ \\
\hline Dlrhizmet $\rightarrow$ Dlrsanayi & $\begin{array}{c}0,1400(1) \\
{[0,9540]}\end{array}$ \\
\hline Dlrsanayi $\rightarrow$ Dlrhizmet & $\begin{array}{c}1,2816(1) \\
{[0,4920]}\end{array}$ \\
\hline Dlrhizmet $\rightarrow$ Dlrtarim & $\begin{array}{c}5,0400(2) \\
{[0,1280]}\end{array}$ \\
\hline Dlrtarim $\rightarrow$ Dlrhizmet & $\begin{array}{c}0,1465(1) \\
{[0,9320]}\end{array}$ \\
\hline
\end{tabular}

Tablo 10'da sunulan Karadeniz Bölgesine ait nedensellik analizi sonuçlarına göre genel ekonomik büyümeden hizmetler sektörüne doğru tek yönlü nedensellik ilişkisi söz konusudur. Genel ekonomik büyüme ile sanayi sektörü büyümesinin karşılıklı nedensellik ilişkisine sahip olduğu tablodan gözlenmektedir. Sektörler arasındaki ilişkiye bakıldığında sadece tarım sektöründeki gelişmenin hizmetler sektöründeki gelişme üzerinde anlamlı bir etkisinin söz konusu olduğu dikkatleri çekmektedir.

Tablo: 10

Karadeniz Bölgesi İçin Dumitrescu ve Hurlin Nedensellik Analizi

\begin{tabular}{|l|c|}
\hline Nedenselliğin Yönü & $\begin{array}{c}\text { Test istatistiği } \\
\text { (Z-bar) }\end{array}$ \\
\hline Dlrgsyih $\rightarrow$ Dlrhizmet & $6,9341^{* *}(1)$ \\
& {$[0,0380]$} \\
\hline Dlrhizmet $\rightarrow$ Dlrgsyih & $2,3950(1)$ \\
& {$[0,2380]$} \\
\hline Dlrgsyih $\rightarrow$ Dlrsanayi & $12,5787^{* *}(2)$ \\
& {$[0,0420]$} \\
\hline Dlrsanayi $\rightarrow$ Dlrgsyih & $10,2403^{*}(2)$ \\
& {$[0,0700]$} \\
\hline Dlrgsyih $\rightarrow$ Dlrtarim & $5,5340(2)$ \\
\hline \multirow{2}{*}{ Dlrtarim $\rightarrow$ Dlrgsyih } & {$[0,1560]$} \\
\hline
\end{tabular}




\begin{tabular}{|c|c|}
\hline Dlrtarim $\rightarrow$ Dlrsanayi & $\begin{array}{c}1,8516(1) \\
{[0,2760]}\end{array}$ \\
\hline Dlrsanayi $\rightarrow$ Dlrtarim & $\begin{array}{c}4,9715(2) \\
{[0,1780]}\end{array}$ \\
\hline Dlrhizmet $\rightarrow$ Dlrsanayi & $\begin{array}{c}1,1665(1) \\
{[0,6320]}\end{array}$ \\
\hline Dlrsanayi $\rightarrow$ Dlrhizmet & $\begin{array}{c}3,1226(1) \\
{[0,1660]}\end{array}$ \\
\hline Dlrhizmet $\rightarrow$ Dlrtarim & $\begin{array}{c}5,6300(2) \\
{[0,1480]}\end{array}$ \\
\hline Dlrtarim $\rightarrow$ Dlrhizmet & $\begin{array}{c}4,5102^{*}(1) \\
{[0,0740]}\end{array}$ \\
\hline
\end{tabular}

Tablo 11'de Akdeniz Bölgesine ait nedensellik analizi sonuçları raporlanmıştır. Tablodan genel ekonomik büyümeden hizmetler ve tarım sektörüne doğru \%5 düzeyinde anlamlı bir nedensellik ilişkisinin söz konusu olduğu gözlenmektedir. Sektörler arasındaki ilişki incelendiğinde ise sanayi sektöründen tarım sektörüne doğru tek yönlü; hizmetler sektörü ile tarım sektörü arasında ise çift yönlü olmak üzere anlamlı ve güçlü bir nedensellik ilişkisi bulunduğu dikkat çekici bir bulgu olarak karşımıza çıkmaktadır. Akdeniz Bölgesi için tarım ve hizmet sektörleri arasındaki karşılıklı ilişkiyi ilgili sektörler arasında Hirshman (1958)'ın ifade ettiği ileri ve geri bağlantı mekanizmasının işlediği şeklinde yorumlayabiliriz. İlgili sektörlerin birbirlerinin girdi ve çıktılarına ihtiyaç duydukları ve bu kapsamda da gerekli iletişimi gerçekleştirdiği ifade edilebilir. Akdeniz Bölgesinde hem sanayi hem de hizmetler sektörü büyüme oranı tarım sektörü büyüme oranının nedeni olarak belirlenmiştir. $\mathrm{Bu}$ sonuç özellikle imalat sanayindeki daha yüksek verimli üretim teknolojilerinin tarım sektörüne yayılma eğilimini ve bu şekilde sektörel verimlilik seviyelerinin yakınsama eğilimine gireceğini savunan Neoklasik argümanı doğrular niteliktedir. Ayrıca Akdeniz Bölgesi için ekonomik büyümeye ivme kazandıran sektörlerin hizmetler ve tarım sektörleri olduğu çalışmadan elde edilen bir diğer çıkarımdır. Akdeniz Bölgesinin turizm potansiyeli göz önüne alındığında ilgili bulgu şaşırtıcı değildir.

Tablo: 11

\section{Akdeniz Bölgesi İçin Dumitrescu ve Hurlin Nedensellik Analizi}

\begin{tabular}{|c|c|}
\hline Nedenselliğin Yönü & $\begin{array}{l}\text { Test istatistiği } \\
\text { (Z-bar) }\end{array}$ \\
\hline Dlrgsyih $\rightarrow$ Dlrhizmet & $\begin{array}{c}5,5760^{* *}(1) \\
{[0,0420]}\end{array}$ \\
\hline Dlrhizmet $\rightarrow$ Dlrgsyih & $\begin{array}{c}1,3558(1) \\
(0,2920]\end{array}$ \\
\hline Dlrgsyih $\rightarrow$ Dlrsanayi & $\begin{array}{c}1,3210(1) \\
{[0,440]}\end{array}$ \\
\hline Dlrsanayi $\rightarrow$ Dlrgsyih & $\begin{array}{c}2,0277(1) \\
{[0,1860]}\end{array}$ \\
\hline Dlrgsyih $\rightarrow$ Dlrtarim & $\begin{array}{c}6,4676^{* *}(1) \\
{[0,0240]}\end{array}$ \\
\hline Dlrtarim $\rightarrow$ Dlrgsyih & $\begin{array}{c}0,6000(1) \\
{[0,6780]}\end{array}$ \\
\hline Dlrtarim $\rightarrow$ Dlrsanayi & $\begin{array}{c}0,3231(1) \\
{[0,8180]}\end{array}$ \\
\hline Dlrsanayi $\rightarrow$ Dlrtarim & $\begin{array}{c}11,5906^{* *}(1) \\
{[0,0160]}\end{array}$ \\
\hline Dlrhizmet $\rightarrow$ Dlrsanayi & $\begin{array}{c}0,6344(2) \\
{[0,7300]} \\
\end{array}$ \\
\hline Dlrsanayi $\rightarrow$ Dlrhizmet & $\begin{array}{c}3,4912(1) \\
{[0,1080]}\end{array}$ \\
\hline
\end{tabular}




\begin{tabular}{|c|c|}
\hline Dlrhizmet $\rightarrow$ Dlrtarim & $\begin{array}{c}4,2629^{* *}(1) \\
{[0,0400]}\end{array}$ \\
\hline Dlrtarim $\rightarrow$ Dlrhizmet & $\begin{array}{c}9,5323^{* * *}(1) \\
{[0,000]}\end{array}$ \\
\hline
\end{tabular}

Doğu Anadolu Bölgesine ilişkin Dumitrescu ve Hurlin nedensellik analizi sonuçları Tablo 12'de sunulmuştur. Genel ekonomik büyüme ile sanayi ve özellikle tarım sektörü arasında çift yönlü anlamlı nedensellik ilişkisinin söz konusu olduğu gözlenmektedir. Ayrıca genel ekonomik büyümenin hizmetler sektörünü beslediği de elde edilen diğer bir bulgu olarak karşımıza çıkmaktadır. Sektörler arasındaki ilişki üzerine odaklanıldığında sanayi sektöründen tarım sektörüne doğru tek yönlü \%1 anlamlılık düzeyinde bir nedensellik ilişkisi olduğu ve söz konusu bu ilişkinin sanayi sektöründen tarım sektörüne doğru ileri bağlantı mekanizmasını doğrular nitelikte bulgular sunduğu ifade edilebilir. Doğu Anadolu Bölgesi için son olarak hizmetler ve tarım sektörleri arasında çift yönlü bir nedensellik iliş̧kisi tespit edilmiştir. İlgili bulgu hizmet ve tarım sektörleri arasında ileri ve geri bağlantı ilişkisinin varlığını kanıtlamaktadır. Ayrıca sanayi ve hizmetler sektörlerinden tarım sektörüne doğru belirlenen nedensellik ilişkisi Neoklasik argümanı doğrulayarak sanayi ve hizmetler sektöründeki yüksek verimliliğe sahip üretim tekniklerinin tarım sektörüne yayılma eğilimini ve böylece sektörel verimlilik seviyelerinin yakınsaklığını teşvik ettiğini ortaya koymuştur. Gerek genel ekonomik büyüme ve gerekse de diğer sektörlerle olan nedensellik ilişkileri göz önüne alındığında Doğu Anadolu Bölgesinde öncü sektörün tarım sektörü olduğu vurgulanabilir.

Tablo: 12

Doğu Anadolu Bölgesi İçin Dumitrescu ve Hurlin Nedensellik Analizi

\begin{tabular}{|c|c|}
\hline Nedenselliğin Yönü & $\begin{array}{c}\text { Test istatistiği } \\
\text { (Z-bar) }\end{array}$ \\
\hline Dlrgsyih $\rightarrow$ Dlrhizmet & $\begin{array}{c}6,1922^{* *}(1) \\
{[0,0380]}\end{array}$ \\
\hline Dlrhizmet $\rightarrow$ Dlrgsyih & $\begin{array}{c}4,2258(2) \\
{[0,1900]}\end{array}$ \\
\hline Dlrgsyih $\rightarrow$ Dlrsanayi & $\begin{array}{c}6,6524 * *(1) \\
{[0,0340]}\end{array}$ \\
\hline Dlrsanayi $\rightarrow$ Dlrgsyih & $\begin{array}{c}7,3671^{* *}(1) \\
{[0,0440]}\end{array}$ \\
\hline Dlrgsyih $\rightarrow$ Dlrtarim & $\begin{array}{c}11,8451^{* * *}(1) \\
{[0,0100]}\end{array}$ \\
\hline Dlrtarim $\rightarrow$ Dlrgsyih & $\begin{array}{c}7,5765^{* *}(1) \\
{[0,0180]}\end{array}$ \\
\hline Dlrtarim $\rightarrow$ Dlrsanayi & $\begin{array}{c}1,9830(1) \\
{[0,2200]}\end{array}$ \\
\hline Dlrsanayi $\rightarrow$ Dlrtarim & $\begin{array}{c}19,6671^{* * * *}(1) \\
{[0,0020]}\end{array}$ \\
\hline Dlrhizmet $\rightarrow$ Dlrsanayi & $\begin{array}{c}1,3669(1) \\
{[0,4060]}\end{array}$ \\
\hline Dlrsanayi $\rightarrow$ Dlrhizmet & $\begin{array}{c}0,6327(1) \\
{[0,7180]}\end{array}$ \\
\hline Dlrhizmet $\rightarrow$ Dlrtarim & $\begin{array}{c}5,5796^{*}(2) \\
{[0,0920]}\end{array}$ \\
\hline Dlrtarim $\rightarrow$ Dlrhizmet & $\begin{array}{c}4,5821^{*}(1) \\
{[0,0700]}\end{array}$ \\
\hline
\end{tabular}


Son olarak Güney Doğu Anadolu Bölgesi için nedensellik bulgularına Tablo 13'te yer verilmiştir. Bölge için edinilen bulguların Doğu Anadolu Bölgesi ile benzerlik taşıdığ tablodan görülmektedir. Sonuçlara göre genel ekonomik büyümeden hizmetler sektörüne doğru ve sanayi sektöründen genel ekonomik büyümeye doğru tek yönlü bir nedensellik ilişkisi söz konusu iken genel ekonomik büyüme ile tarım sektörü arasında çift yönlü anlamlı nedensellik ilişkisi mevcuttur. İlgili bulgular çerçevesinde Güney Doğu Anadolu Bölgesi için de ekonomik büyümeyi besleyen öncü sektörün tarım sektörü olduğu yönünde çıkarımda bulunulabilir. Güney Doğu Anadolu Bölgesi için sektörler arasındaki dinamik ilişki mercek altına alındığında sanayi sektöründen tarım sektörüne doğru tek yönlü, hizmetler sektörü ile tarım sektörü arasında ise çift yönlü olmak üzere anlamlı bir nedensellik ilişkisi olduğu görülmüştür. Bu kapsamda bölge için tarım ve hizmetler sektörü arasında karşılıklı ileri ve geri bağlantı mekanizmasının işlediği ifade edilebilir.

Tablo: 13

\section{Güney Doğu Anadolu Bölgesi İçin Dumitrescu ve Hurlin Nedensellik Analizi}

\begin{tabular}{|c|c|}
\hline Nedenselliğin Yönü & $\begin{array}{c}\text { Test istatistiği } \\
\text { (Z-bar) }\end{array}$ \\
\hline Dlrgsyih $\rightarrow$ Dlrhizmet & $\begin{array}{c}8,3117^{*}(2) \\
{[0,0560]}\end{array}$ \\
\hline Dlrhizmet $\rightarrow$ Dlrgsyih & $\begin{array}{c}1,0843(1) \\
{[0,5000]}\end{array}$ \\
\hline Dlrgsyih $\rightarrow$ Dlrsanayi & $\begin{array}{c}2,5034(1) \\
{[0,2060]}\end{array}$ \\
\hline Dlrsanayi $\rightarrow$ Dlrgsyih & $\begin{array}{c}5,4114^{* *}(1) \\
{[0,0360]}\end{array}$ \\
\hline Dlrgsyih $\rightarrow$ Dlrtarim & $\begin{array}{c}6,1781^{* *}(1) \\
{[0,0220]}\end{array}$ \\
\hline Dlrtarim $\rightarrow$ Dlrgsyih & $\begin{array}{c}6,70399^{* *}(1) \\
{[0,0140]}\end{array}$ \\
\hline Dlrtarim $\rightarrow$ Dlrsanayi & $\begin{array}{c}3,3213(1) \\
{[0,1220]}\end{array}$ \\
\hline Dlrsanayi $\rightarrow$ Dlrtarim & $\begin{array}{c}6,5210^{*}(2) \\
{[0,0780]}\end{array}$ \\
\hline Dlrhizmet $\rightarrow$ Dlrsanayi & $\begin{array}{c}-0,7636(1) \\
{[0,6320]}\end{array}$ \\
\hline Dlrsanayi $\rightarrow$ Dlrhizmet & $\begin{array}{c}0,2284(1) \\
{[0,8800]}\end{array}$ \\
\hline Dlrhizmet $\rightarrow$ Dlrtarim & $\begin{array}{c}5,5359^{*}(1) \\
{[0,0580]}\end{array}$ \\
\hline Dlrtarim $\rightarrow$ Dlrhizmet & $\begin{array}{c}9,9421^{* *}(2) \\
{[0,0260]}\end{array}$ \\
\hline
\end{tabular}

\section{Sonuç}

Bu çalışmada Türkiye ekonomisi için gerek tarım, sanayi ve hizmet sektörlerinde yaratılan ekonomik büyüme ile genel ekonomik büyüme arasındaki nedensellik ilişkisinin gerekse de sektörler arasındaki ileri ve geri doğru bağlanım mekanizmalarının 2004-2017 dönemi itibariyle 81 il düzeyinde araştırılması amaçlanmıştır. Sektörler arasındaki nedensellik ilişkilerinin belirlenmesinde Dumitrescu ve Hurlin panel nedensellik yaklaşımından yararlanılmıştır. Edinilen sonuçlara göre, Türkiye'de iller bazında tarım sektöründeki gelişme ile genel ekonomik büyüme arasında güçlü bir geri besleme ilişkisi bulunmaktadır. Ayrıca sanayi sektöründen genel ekonomik büyümeye ve genel ekonomik 
Mert, N. \& Z. Abdioğlu (2021), “Türkiye'de Tarım, Sanayi ve Hizmet Sektörleri

Arasındaki Nedensellik İlișkisinin Analizi”, Sosyoekonomi, 29(50), 317-336.

büyümeden hizmetler sektörüne doğru tek yönlü bir nedensellik ilişkisi tespit edilmiştir. Bulgular sanayi sektörü üretimindeki büyümeden tarımsal üretime doğru tek yönlü, tarım ve hizmetler sektörü arasında ise karşılıklı nedensellik ilişkisi olduğunu kanıtlamıştır. Türkiye geneli bulguları tarım ve hizmetler sektörleri arasında ileri ve geri bağlanım mekanizmasının çalıştığını, sanayi sektöründen tarım sektörüne doğru sadece ileri bağlanım mekanizmasının geçerli olduğunu ortaya koymuştur. Bunun yanı sıra sanayi ve hizmetler sektörlerinden tarım sektörüne doğru belirlenen nedensellik ilişkisi Neoklasik argümanı doğrulayarak sanayi ve hizmetler sektöründeki yüksek verimliliğe sahip üretim teknolojilerinin tarım sektöründe kullanım eğilimini ortaya koymuştur.

Çalışmada ayrıca genel ekonomik büyüme ile sektörel büyüme arasındaki ilişki yedi alt bölge düzeyinde araştırılmıştır. Bölgesel düzeyde yapılan analiz sonuçlarına göre, Marmara Bölgesi'nde sektörlere ait büyüme ile genel ekonomik büyüme arasında karşılıklı bir ilişkiye rastlanamamış ancak hizmetler sektöründen tarım sektörüne doğru tek yönlü bir nedensellik ilişkisi olduğu görülmüştür. Ege Bölgesinde hizmetler sektöründeki büyümenin genel ekonomik büyümeyi beslediği; sanayi ve hizmetler sektörüne ait büyümenin ise tarım sektörünü etkilediği kanıtlanmıştır. İç Anadolu Bölgesi’nde beklenildiği üzere tarım sektörü ile genel ekonomik büyüme arasında karşılıklı bir ilişki olduğu, sanayi sektöründeki gelişmeden genel ekonomik büyümeye ve tarım sektörü büyümesine doğru tek yönlü bir nedenselliğin olduğu tespit edilmiştir. Karadeniz Bölgesi için yapılan analiz bulgularına bakıldığında, sanayi sektöründeki büyüme ile genel ekonomik büyüme arasında güçlü bir geri besleme ilişkisi olduğu, genel ekonomik büyüme ve tarım sektöründeki büyümenin ise hizmetler sektörünü beslediği görülmüştür. Akdeniz Bölgesi'ne gelindiğinde genel ekonomik büyümenin hizmetler ve tarım sektörlerini tek yönlü beslediği, hizmetler sektörü ile tarım sektörü arasında karşılıklı bir ilişki olduğu ve sanayi sektöründen tarım ve hizmetler sektörlerine doğru tek yönlü nedensellik ilişkisi olduğu yönünde bulgulara ulaşılmıştır. Doğu Anadolu Bölgesi'nde genel ekonomik büyüme ile hem tarım hem de sanayi sektöründeki büyüme arasında çift yönlü bir nedensellik ilişkisi olduğu, hizmetler sektörü ve tarım sektörü arasında çift yönlü bir nedensellik ilişkisinin bulunduğu ve sanayi sektöründen tarım sektörüne doğru tek yönlü bir nedensellik ilişkisinin söz konusu olduğu görülmüştür. Son olarak Güney Doğu Anadolu Bölgesi özelinde ise nispeten Doğu Anadolu Bölgesine benzer bulgulara ulaşılmıştır.

Dimutrescu-Hurlin panel nedensellik yaklaşımı çerçevesinde Türkiye geneli için edinilen bulgular ele alınan dönem itibariyle özellikle sanayi ve tarım sektörlerinin genel ekonomik büyümeyi doğrudan uyaran sektörler olduğunu, hizmetler sektörünün ise tarım sektörü üzerinden dolaylı olarak genel ekonomik büyümeyi uyardığını göstermiştir. Ancak ilgili bulguların bölgesel analizlerde farklılaştı̆̆ı gözlenmiştir. Şöyle ki Ege Bölgesi için hizmetler sektörünün, İç Anadolu Bölgesi için sanayi ve tarım sektörlerinin, Akdeniz Bölgesi için tarım ve hizmetler sektörlerinin, Doğu ve Güneydoğu Anadolu Bölgeleri için tarım sektörünün ön plana çıktığı belirlenmiştir. Ege ve Akdeniz Bölgeleri için hizmetler sektörünün kilit sektör olarak belirlenmiş olması kuşkusuz ilgili bölgelerdeki turizm potansiyeli ile açıklanabilir. Doğu ve Güneydoğu Anadolu Bölgeleri için tarım sektörünün kilit sektör olarak ön plana çıkması ilgili bölgelerde ekonomik faaliyetler arasında tarımsal 
faaliyetlerin diğer aktivitelerden daha baskın olmasına bağlanabilir. Benzer şekilde İç Anadolu Bölgesi için sanayi ve tarım sektörlerinin kilit sektör olarak belirlenmiş olması bölgedeki sanayi tesislerinin varlığı ve tarımsal alanların mevcudiyeti ile açıklanabilir.

Sektörler arasındaki ilişki bazında bölgeler itibariyle ortaya çıkan en dikkat çekici bulgu çoğu bölgede tarım ve hizmet sektörlerinin geri besleme ilişkisine sahip olmasıdır. Ayrıca gerek hizmetler sektörü ve gerekse de sanayi sektöründen tarım sektörüne ileri doğru bir bağlanım mekanizması belirlenmiştir. İlgili bulgu tarım sektöründe yüksek verimliğe sahip ileri teknoloji ürünlerine olan ihtiyacı ortaya koymuştur. Özellikle Doğu ve Güneydoğu Anadolu Bölgelerinde sanayi ve hizmetler sektöründen beslenen tarım sektörü bölgenin ekonomik büyümesini uyaran temel sektör olarak karşımıza çıkmaktadır.

Çalışmada edinilen bulgular özetle genel ekonomik büyümeye yön veren öncü sektörlerin bölgelere göre farklılık arz ettiğini, bazı sektörlerin doğrudan olmaktan ziyade diğer sektörler üzerinden dolaylı olarak genel ekonomik büyümeyi uyardığını ve genel anlamda sektörler arasında ileri ve geri bağlanım mekanizmasının çalıştığını ortaya koymuştur. Bu çerçevede Türkiye ekonomisi için sürdürülebilir bir ekonomik büyümeye ulaşmak amacıyla kilit olarak belirlenen sektörlerin geliştirilmesine yönelik uygun politikaların tasarlanması ve bölgesel farklılıkları göz önüne alarak kilit sektörlere ait ekonomik faaliyetlerin teşvik edilmesi son derece önem arz etmektedir.

Ekonominin genel sektörleri kapsamında gerçekleştirilen bu analizin ikinci düzey alt sektörler kapsamında yeniden ele alınması ve özellikle daha uzun bir zaman dilimi kapsamında uzun dönem analizlere uygun veri seti ile çalışılması kuşkusuz daha detaylı bulgulara ulaşmaya olanak sağlayacaktır.

\section{Kaynaklar}

Ahmed, A. \& H. Ahsan (2011), "Contribution of Services Sector in the Economy of Pakistan", PIDE-Working Papers, 79, Pakistan Institute of Development Economics, Islamabad.

Altan, Ş. \& M. Atan \& S. Tokpınar (2015), "Sektörel Etkinlik Ölçümü: Girdi Çıktı Tablosu ve Veri Zarflama Analizi ile Bir Uygulama”, İşletme Araştırmaları Dergisi, 7(2), 214-234.

Arısoy, İ. (2008), “Türkiye'de Sanayi Sektörü-İktisadi Büyüme İlişkisinin Kaldor Hipotezi Çerçevesinde Test Edilmesi”, Discussion Paper, 2008/1, Türkiye Ekonomisi.

Atan, S. (2011), "Türkiye'deki Sektörel Bağlantı Yapısının Girdi Çıktı Yaklaşımı ile İncelenmesi: Yurtiçi Üretim ve İthal Ara Girdi Ayrıştırması”, Ekonomik Yaklaşım, 22(80), 59-78.

Bhagwati, J.N. (1984), "Splintering and Disembodiment of Services and Developing Nation", World Economy, 7, 133-143.

Blades, D. \& D.D. Johnson \& W. Marczewski (1974), Service Activities in Developing Countries, OECD, Paris.

Blunch, N.H. \& D. Verner (2006), "Shared Sectoral Growth Versus the Dual Economy Model: Evidence from Cote d'lvoire, Ghana, and Zimbabwe", African Development Review, 18(3), 283-308. 
Breusch, T. \& A. Pagan (1980), "The Lagrange Multiplier Test and Its Application to Model Specifications in Econometrics", Review of Economic Studies, 47 (1), 239-253.

Chenery, H.B. (1979), Structural Change and Development Policy, Oxford University Press, New York.

Dasgupta, S. \& A. Singh (2005), "Will Services be the New Engine of Indian Economic Growth?", Development and Change, 36(6), 1035-58.

Dumitrescu, E. \& C. Hurlin (2012), "Testing for Granger Non-Causality in Heterogeneous Panels", Economic Modelling, 29(4), 1450-1460.

Ersungur, Ş.M. \& A. Kızıltan (2008), "Türkiye Ekonomisinde Sektörler arası Yapısal BağınlaşmaGirdi Çıktı Yöntemiyle Bir Uygulama”, Atatürk Üniversitesi İktisadi İdari Bilimler Dergisi, 22(2), 17-31.

Ersungur, Ş.M. \& E.D. Ekinci \& A. Takım (2011), "Türkiye Ekonomisinde İthalata Bağımlılıktaki Değişme: Girdi-Çıktı Yaklaşımıyla Bir Uygulama", Atatürk Üniversitesi İIBF Dergisi, Ekonometri ve İstatistik Sempozyumu Özel Sayıs1, 25, 1-11.

Fei, J.C.H. \& G. Ranis (1961), “A Theory of Economic Development”, American Economic Review, 51, 533-565.

Foster McGregor, N. \& J. Pöschl \& R. Stehrer (2012), "Manufacturing Productivity: Effects of Service Sector Innovations and Institutions", Working Paper, 89, The Vienna Institute for International Economic Studies.

Fuchs, V. (1968), “The Service Economy”, National Bureau of Economic Research, New York.

Gemmell, N. \& T.A. Lloyd \& M. Mathew (2000), "Agricultural Growth and Inter-Sectoral Linkages in a Developing Economy”, Journal of Agricultural Economics, 51, 353-370.

Gemmell, N. (1982), "Economic Development and Structural Change, The Role of Service Sector", Journal of Development Studies, 19, 37-66.

Granger, C.W.J. (1969), "Investigating Causal Relations by Econometric Models and Cross-spectral Methods", Econometrica, 37(3), 424-438.

Günçavd1, Ö. \& S. Küçükçiftçi \& A. Bayar (2013), "Economic Development and Structural Change: The Role of the Agriculture Sector in Turkey", Middle East Development Journal, 5(2), $1-29$.

Hirschman, A.O. (1958), Strategy of Economic Development, New Haven, Conn: Yale University Press.

Hwa, E.C. (1989), "The Contribution of Agriculture to Economic Growth: Some Empirical Evidence", içinde: J. Williamson \& V.R. Panchamurchi (eds.), The Balance between Industry and Agriculture in Economic Development, Volume 2, Sector Proportion, New York: The World Bank.

Kaldor, N. (1967), Strategic Factors in Economic Development, New York State School of Industrial and Labor Relations, Cornell University, Ithaca.

Kalmaz, D. \& N. Giritli (2018), “KKTC’de Ekonomik Büyüme ve Sektörel Gelişimin Büyümeye Etkileri”, Gazi Akademik Bakış Dergisi, 11, 199-220.

Kanwar, S. (2000), "Does the Dog Wag the Tail or the Tail the Dog? Cointegration of Indian Agriculture with Non-agriculture”, Journal of Policy Modeling, 22 (5), 533-556. 
Katırcığlu, S. (2002), "Co-Integration and Causality between GDP, Agriculture, Industry and Services Growth in North Cyprus: Evidence from Time Series Data, 1977-2002”, Review of Social, Economic \& Business Studies, 5(6), 173-187.

Kolcu, F. \& N. Yamak (2017), “Türkiye'de Kısa ve Uzun Dönem Sektörel Dinamikler”, Kafkas Üniversitesi İktisadi ve İdari Bilimler Fakültesi Dergisi, 8(15), 81-99.

Kularatne, T. \& S. Sivarajasingham (2014), "Inter-Sectoral Dynamic Growth Linkages: Empirical Evidence form Sri Lanka", Journal of Management, 10 (1), 25-33.

Kuznets, S. (1973), "Modern Economic Growth: Findings and Reflections", The American Economic Review, 63(3), 247-258.

Lewis, W.A. (1954), "Economic Development with Unlimited Supplies of Labor", Manchester School, 22, 139-191.

Nordas, H.K. \& Y. Kim (2013), "The Role of Services for Competitiveness in Manufacturing”, OECD Trade Policy Papers, 148.

Pehlivanoğlu, F. \& M. İnce (2020), "Girdi-Çıktı Analizi Yaklaşımıyla Türkiye Ekonomisinde Sektörlerarası Bağınlaşmanın Uzun Dönemli Analizi”, Sosyoekonomi, 28(44), 169-190.

Pesaran, M.H. \& T. Yamagata (2008), “Testing Slope Homogeneity in Large Panels”, Journal of Econometrics, 142, 50-93.

Pesaran, M.H. (2004), "General Diagnostic Tests for Cross Section Dependence in Panels”, CESifo Working Paper, 1233, 255-60.

Pesaran, M.H. (2007), “A Simple Panel Unit Root Test in the Presence of Cross Section Dependence", Journal of Applied Econometrics, (22), 365-312.

Rashid, A. (2004), "Sectoral Linkages; Identifying the Key Growth Stimulating Sector of the Pakistan Economy”, Working Paper, 27210, Munich Personal RePEc Archive.

Sastry, D. vd. (2003), "Sectoral Linkages and Growth Prospects: Reflections on the Indian Economy", Economic and Political Weekly, 38(24), 2390-2397.

Subramaniam, V. \& M. Reed (2009), “Agricultural Inter Sectoral Linkages and its Contribution to Economics Growth in the Transition Countries", International Association of Agricultural Economists Conference, Beijing, China, August 16-22.

Swamy, P.A.V.B. (1970), "Efficient Inference in A Random Coefficient Regression Model", Econometrica, 38(2), 311-323.

Terzi, H. \& S. Oltulular (2004), “Türkiye'de Sanayileşme ve Ekonomik Büyüme Arasındaki Nedensel İlişki”, Doğuş Üniversitesi Dergisi, 5(2), 219-226.

Thirlwall, A.P. (2006), Growth and Development with Special Reference to Developing Economies, 8th Edition: Palgrave Macmillan.

Wells, H. \& A.P. Thirlwall (2004), "Testing Kaldor's Growth Laws across the Countries of Africa”, African Development Review, 15(2-3), 89-105.

Yamak, N. (2000), “Cointegration, Causality and Kaldor's hypothesis: Evidence from Turkey, 19461995”, Gazi Üniversitesi İktisadi ve İdari Bilimler Fakültesi Dergisi, 2(1), 75-80.

Yamak, R. \& U. Sivri (1997), “Ekonomik Büyüme ve Kaldor Yasası: Türkiye Örneği, 1979-1994”, İktisat, Issletme ve Finans Dergisi, 12(139), 9-21.

Yamak, R. vd. (2016), “A Re-examination of Kaldor's Engine of Economic Growth Hypothesis for the Turkish Economy”, Acta Universitatis Danubius Economica), 12(4), 347-357. 
Yao, S. (2000), “How Important is Agriculture in China's Economic Growth?”, Oxford Development Studies, 28(1), 33-49.

Yetiz, F. \& C. Özden (2017), "Analysis of Causal Relationship among GDP, Agricultural, Industrial and Services Sector Growth in Turkey", Ömer Halis Demir Üniversitesi İktisadi ve İdari Bilimler Fakültesi Dergisi, 10(3), 75-84.

Yıldız, N. \& U. Akduğan (2014), "Girdi-Çıktı Tabloları ile Sektörler Arası İlişkilerin Analizi: Seçilmiş Ülke Örnekleri”, Akademik Bakış Dergisi, 44. 